\title{
Computed tomography of the lungs in novel corona virus (COVID-19) infection
}

\author{
Wei Lai ${ }^{1} \cdot$ Chuxing Xie ${ }^{2,3} \cdot$ Haien Pan $^{3} \cdot$ Miao Fan ${ }^{4} \cdot$ Jianxin Liu ${ }^{1}$ \\ Received: 26 February 2020 / Revised: 4 March 2020 / Accepted: 12 March 2020/Published online: 2 May 2020 \\ (C) Springer-Verlag GmbH Germany, part of Springer Nature 2020
}

\section{Dear Editors,}

Novel corona virus 2019 (COVID-19) disease emerged at the end of 2019 in Wuhan City in the Hubei Province of China [1]. There are, to date, few reports of imaging in infected children. We report on two children diagnosed with COVID-19.

The first case is a 12-year-old boy who was admitted to the hospital with 2 days of cough. The boy's main symptoms were dry cough, fever and general weakness. The second case is a 16-year-old boy who was admitted to the hospital after 1 day of fever and cough without obvious inducement. Both live in Wuhan City, where they were at the onset of symptoms.

COVID-19 nucleic acid tests were positive before the CT scan in both boys. In Case 1, no obvious abnormality was found in the lungs on the first scan of the chest 4 days after symptom onset. Repeat examination after 4 more days showed multiple patches of subpleural ground-glass. Reexamination after yet another 4 days showed partial resolution in the right lung, but a new nodule was detected (Fig. 1). The boy's condition improved after 17 days of antiviral and symptomatic treatment, and he was discharged.

Jianxin Liu

373066547@qq.com

1 Department of Radiology,

The Affiliated Dongguan Children's Hospital

of Guangdong Medical University,

Dongguan 523325, Guangdong, China

2 Department of Pediatrics,

The Affiliated Dongguan Children's Hospital

of Guangdong Medical University,

Dongguan, Guangdong, China

3 Department of Inpatients,

The Ninth People's Hospital of Dongguan,

Dongguan, Guangdong, China

4 Department of Radiology, The First Affiliated Hospital, Sun Yat-sen University, Guangzhou, Guangdong, China

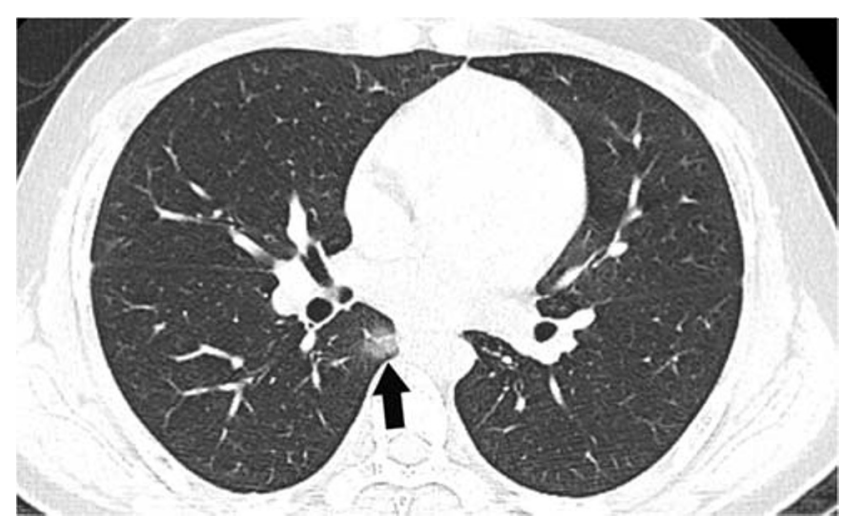

Fig. 1 Unenhanced axial chest CT image in a 12-year-old boy with COVID-19 infection 8 days after onset shows a ground-glass lesion (arrow) medially in the right lower lobe

In Case 2, patchy ground-glass opacification and vascular dilatation was seen in the left upper lobe on the CT examination on Day 2 after admission. Re-examination after an interval of 13 days showed resolution of the ground-glass changes, but multiple nodular lesions with a ground-glass halo were seen in the right upper lobe (Fig. 2). The boy's condition

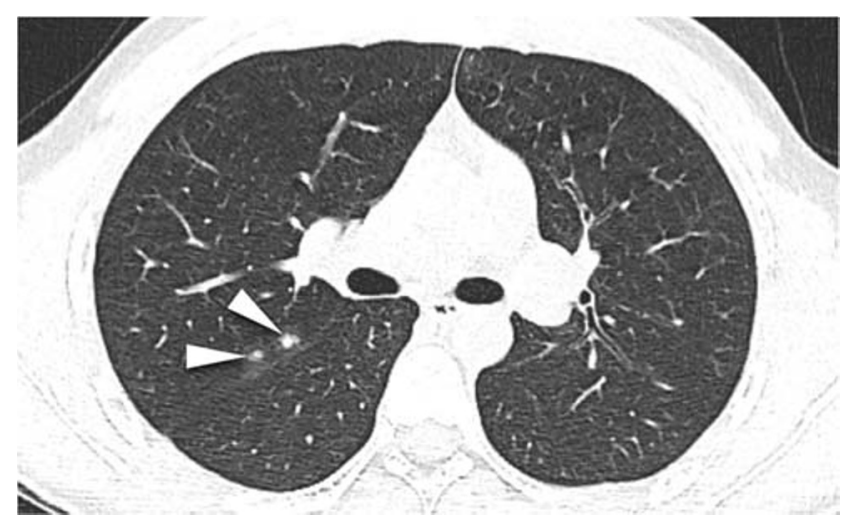

Fig. 2 Unenhanced axial chest CT image in a 16-year-old boy with COVID-19 infection 15 days after onset shows several small subpleural nodules (arrowheads) with ground-glass halo in the right upper lobe 
improved after 29 days of antiviral and symptomatic treatment, and he was discharged.

In our experience, there are differences in CT findings between children and adults infected with COVID-19. Children seem to have smaller, mainly ground-glass nodules, and larger consolidations or white-out is rare. The clinical symptoms seem relatively mild in children [2-5].

\section{Compliance with ethical standards}

Conflicts of interest None

\section{References}

1. World Health Organization (2020) Novel coronavirus - China. https://www.who.int/csr/don/12-january-2020-novel-coronaviruschina/en/. Accessed 12 Jan 2020
2. Xu Z, Shi L, Wang Y et al (2020) Pathological findings of COVID19 associated with acute respiratory distress syndrome. Lancet. https://www.thelancet.com/journals/lancet/article/PIIS22132600(20)30076-X/fulltext. Accessed 9 March 2020

3. Shi H, Han X, Zheng C (2020) Evolution of CT manifestations in a patient recovered from 2019 novel coronavirus (2019-nCoV) pneumonia in Wuhan, China. Radiology. https://pubs.rsna.org/doi/10. 1148/radiol.2020200269. Accessed 9 March 2020

4. Fang Y, Zhang H, Xu Y et al (2020) CT manifestations of two cases of 2019 novel coronavirus (2019-nCoV) pneumonia. Radiology. https://pubs.rsna.org/doi/full/10.1148/radiol.2020200280. Accessed 9 March 2020

5. Kanne JP (2020) Chest CT findings in 2019 novel coronavirus (2019-nCoV) infections from Wuhan, China: key points for the radiologist. Radiology. https://pubs.rsna.org/doi/10.1148/radiol. 2020200241. Accessed 9 March 2020

Publisher's note Springer Nature remains neutral with regard to jurisdictional claims in published maps and institutional affiliations. 